DOI: $10.17148 /$ IARJSET.2021.8801

\title{
Investigation of Medicinal Plants as an Alternative Medicine for Paracetamol
}

\author{
Meena Jha ${ }^{1}$, Asita Elengoe ${ }^{2 *}$ \\ PG - Department of Biotechnology, Faculty of Science, Lincoln University College, 47301 Petaling Jaya, \\ Selangor, Malaysia ${ }^{1}$ \\ Associate Professor, Department of Biotechnology, Faculty of Science, Lincoln University College, 47301 \\ Petaling Jaya, Selangor, Malaysia ${ }^{2 *}$
}

\begin{abstract}
Everyone wants good health, which can be promoted and maintained by encouraging healthy habits. Sometimes, people depend on medicines for staying fit. Medicines are effective but also cause some side effects. In order to get rid of pain and fever dependence on Paracetamol is observed. Worldwide, Paracetamol (Acetaminophen) or PCM can be defined as a single of the most widely used pain-relieving and antipyretic drugs. Nevertheless, it can't be denied that the consumption of Paracetamol directly or indirectly affects everyone depending upon body structure, gender, and age. The study reveals that regular use of Paracetamol causes toxicity and may gradually impact health and causes long-term side effects like fatigue, persistent anemia, and also threat to vital organs like the liver and kidneys. Plants are the beacon of hope during the pandemic time too because medicinal plants possess specific bioactive compounds, alkaloids that can be used for medications without any side effects and can overtake the production of artificial drugs. In this study, the use of the traditional herbs such as tulsi, turmeric, ginger, and neem leaf as an effective alternative medicine to Paracetamol among people in the rural field practice area of Dehradun, India was investigated. One-hundred sixteen participants involved in this study. The results show that $72.4 \%$ participants believed that paracetamol causes side effects and natural herbs alternative to paracetamol. The natural herbs are very effective. They possess several medical effects such as anti-oxidant, anti-viral, anti-bacterial, anti-inflammatory and anti-cancer properties.
\end{abstract}

Keywords: Paracetamol; Toxicity; Natural herbs

\section{INTRODUCTION}

Health is wealth. Everyone wants good health, which can be promoted and maintained by encouraging healthy habits. Sometimes people depend on medicines for staying fit. Medicines are effective but also cause some side effects. Acetaminophen (Paracetamol) is a commonly used non-narcotic, non-NSAID analgesic that is effective against a variety of pain types, but the aftermaths of overdose can be severe [1-3]. An unintentional cumulative overdose is an emerging problem due to its widespread availability as a single agent and its formulation in fixed-ratio combination analgesic products for the potential additive or synergistic analgesic effect and/or reduced side effects [4, 5].

Paracetamol is available in India in a variety of formulations, including liquid suspension, drops, pills, injectable, and rectal suppositories, with varied strengths $(120 / 125 / 150 / 250 / 500 \mathrm{mg} / 5 \mathrm{~mL})$, according to the Indian Academy of Pediatrics. Paracetamol comes in solid (tablets and capsules) and liquid (solution and suspension) dosage forms, as well as a semi-solid dosage form (as a suppository) [6]. Although research literature suggests that an injectable dose form of paracetamol could be made, there is no injectable or infusion paracetamol accessible. When used orally, paracetamol is quickly absorbed from the gastrointestinal tract. The maximum blood concentration is observed to occur within 10-90 minutes [6]. It's a powerful analgesic and antipyretic that's as efficient as aspirin for treating mild to severe pain. Acetaminophen, unlike aspirin, does not affect platelet activity. It also generates less stomach discomfort and is not linked to Reye syndrome [7]. Acetaminophen's main disadvantage is that it has no clinically significant antiinflammatory qualities [7-10].

Medicinal plant analysis has been done for a long time, especially when it comes to determining the quality of a plant. The sensory organs, olfactory receptors, touch, taste, smell, and appearance were used as the first simple technique. Then progressively incorporate more complex instrumental approaches into your performance. Nature has bestowed so many bounties to mankind to overcome disease and disorders by using in the form of trees, herbs to overcome diseases and disorders. Since, time immemorial, it has been mentioned in Vedas $600 \mathrm{BC}$, that plants play an important role in meeting daily demands and are an important part of our health care system. The use of herbs in Charak Samhita, Ayurvedic Scriptures are also mentioned. Plants are the beacon of hope during the pandemic time too because 


\section{DOI: 10.17148/IARJSET.2021.8801}

Medicinal Plants possess specific Bioactive compounds, alkaloids that can be used for medications without any side effects and can overtake the production of artificial drugs.

In this study, we analyzed the traditional use of herbs among communities in the Rural Field practice area of Dehradun, India. The medicinal plants were chosen as an effective alternative to Paracetamol medicine to cure health issues. Because these plants have several health-beneficial effects such as anti-inflammatory, antiviral, and antibacterial properties without any side effects. Regularly doing moderate physical exercises, intake of a balanced diet, meditation, yoga can result in a complete state of physical, mental, and social well-being.

\section{METHODOLOGY}

A community-based cross-sectional online survey study was carried out in the Rural Field practice area of Dehradun, India, and 116 respondents including males and females were participated. The survey was about the investigation of medicinal plants as an alternative medicine for paracetamol between June to December 2020 in India. Google form was generated and distributed through Whatapps, emails, Facebook and other social media. Participants agreed voluntarily and their consent was taken before their participation in the survey. The data was collected and analyzed using the Microsoft Excel.

\section{RESULTS AND DISCUSSION}

One hundred sixteen informants were interviewed. $72.4 \%$ of people believed that paracetamol affects everyone and natural medicinal alternatives are very effective (Fig. 1). Furthermore, $86.2 \%$ of people believed that a medicinal plant has similar properties to conventional pharmaceutical drugs (Fig. 2).

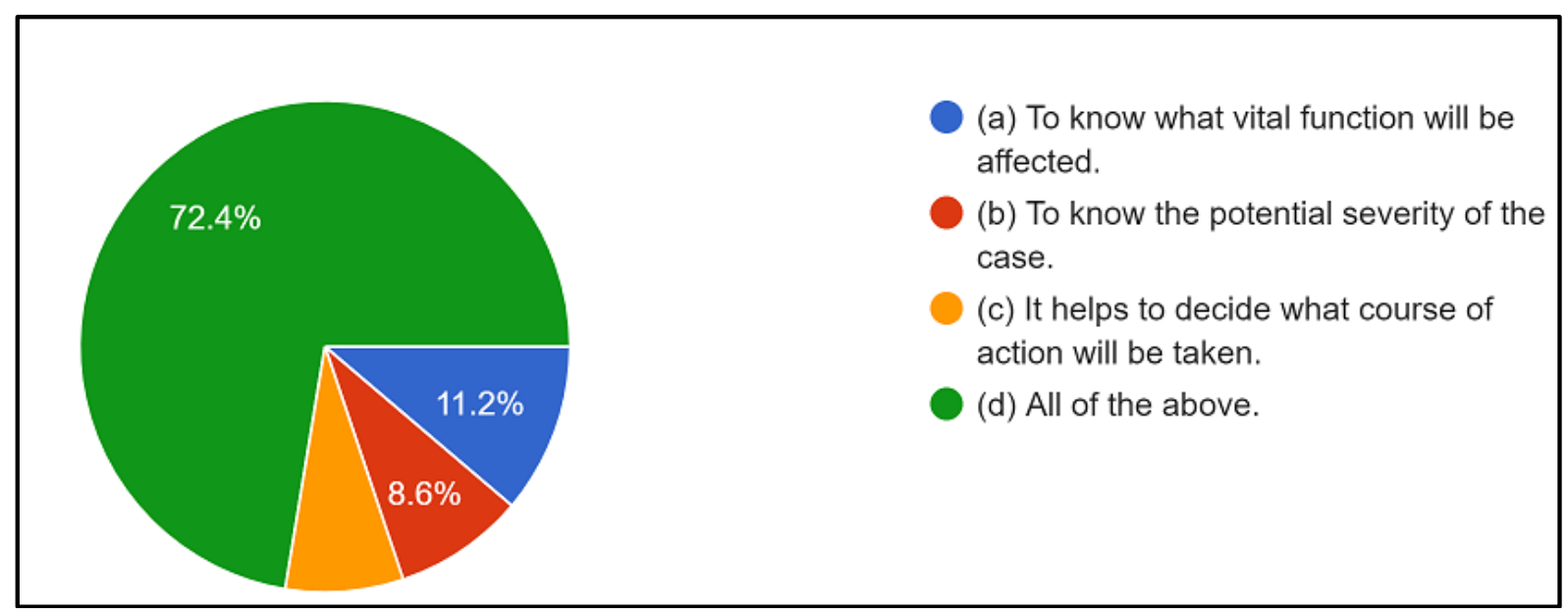

Fig. 1. Pie chart about the toxicity of paracetamol. Paracetamol affects everyone differently based on size, weight, health, consumption. Medicinal plants are alternative for paracetamol.

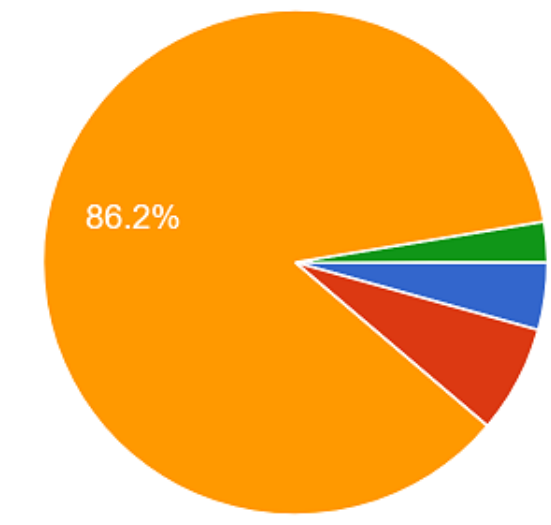

(a) A plant that is only used in food.

(b) A plant that is available only on mountains.

(c) A plant that has similar properties to conventional pharmaceutical drugs

(d) A plant that is deadly.

Fig. 2. Pie chart shows that a plant that has similar properties to conventional pharmaceutical drugs.

It has been observed that traditional herbs and medicines are vital but often overlooked and underestimated in health 


\title{
International Advanced Research Journal in Science, Engineering and Technology
}

\author{
Vol. 8, Issue 8, August 2021
}

\section{DOI: 10.17148/IARJSET.2021.8801}

care sectors. Various ethnomedical plants have been widely used by rural areas to cure various disorders [11]. Traditional indigenous knowledge shared by grandparents and forefathers has a social and cultural heritage that is truly significant in health care. It is now done in practically every country on the planet. In the form of alternative medicine, it is currently in high demand. Traditional medicine systems have used ethnomedicinal plants to treat a variety of diseases [12]. Medicinal plants are used by almost $80 \%$ of the people in underdeveloped nations to treat ailments and sustain and improve the lives of their generation. Traditional knowledge has developed in indigenous societies through oral and discipleship processes and has a lengthy historical-cultural legacy and rich natural resources. Traditional indigenous knowledge is critical in the creation of herbal treatments and the isolation of bioactive ingredients that serve as a precursor to semisynthetic pharmaceuticals [13]. It has proven to be the most effective criterion for the creation of innovative medications. A total of 92 medicinal species were discovered, comprising 91 vascular plant species from 50 different families and one fungus, Morchella of the Ascomycetes family Morchellaceae. According to the findings, the Asteraceae family has eight species, followed by the Lamiaceae family with seven species, and the Rosaceae family with seven species, each with a higher number of therapeutic plants. Moraceae, Asclepiadaceae, Polygonaceae, Brassicaceae, Solanaceae, Cucurbitaceae, and Amaryllidaceae each contributed three species. Poaceae, Pinaceae, Zingiberaceae, Chenopodiaceae, Plantaginaceae, Apiaceae, Fabaceae, and Zygophylaceae each contributed two species, while the remaining eight families, Poaceae, Pinaceae, Zingiberaceae, Chenopodiaceae, Plantaginaceae, Apiaceae, Fabaceae, and Zygophylaceae. The Asteraceae, Lamiaceae, and Rosaceae families were also found to have a large number of therapeutic plants. Traditional health healers are critical in meeting the basic health needs of the area's economically disadvantaged residents. The majority of individuals either follows local healers' recipes or chooses wild medicinal herbs that they recommend [14]. Some elders were also skilled at preserving therapeutic plant pieces for later use. Traditional medicinal plant knowledge is dwindling in the area due to a lack of interest among the younger generation in acquiring this cultural asset. In addition, most traditional health practitioners and wise elders are hesitant to share their recipes [15]. As a result, traditional knowledge in the area is dwindling as the elderly pass away. Plant names in the vernacular are the foundations of ethnomedicinal variety knowledge. They can help to resolve any confusion about the identification of medicinal plants in a certain area. It also aids in the preservation of traditional medicinal plant knowledge.

\section{CONCLUSION}

All of the plants tested showed significant efficacy, confirming their different traditional usage as well as their capacity to treat common ailments. As a result, more research into these plants is needed, including extracting active chemicals that can be processed into novel and effective medicines, as well as studying their methods of action.

\section{REFERENCES}

1. Acetaminophen Toxicity. 2020. Retrieved from: https://emedicine.medscape.com/article/820200-overview. facts/paracetamol/\#: :text=Paracetamol\%20is\%20a\%20pharmaceutical\%20drug,pain\%20(when\%20combined $\% 20$ with $\% 20$ codeine).

3. Raffa RB, Pergolizzi Jr JV, Taylor Jr R, Decker JF, Patrick JT. Acetaminophen (paracetamol) oral absorption and clinical influences. Pain Practice. 2014 Sep;14(7):668-77.

4. Fendrick AM, Greenberg BP. A review of the benefits and risks of nonsteroidal anti-inflammatory drugs in the management of mild-tomoderate osteoarthritis. Osteopathic medicine and primary care. $2009 \mathrm{Dec} ; 3(1): 1-7$.

5. James LP. Acetaminophen: Pathology and clinical presentation of hepatotoxicity. In Drug-Induced Liver Disease 2013 Jan 1 (pp. $331-341$ ). Academic Press.

6. Roy J. An introduction to pharmaceutical sciences: Production, chemistry, techniques and technology. Elsevier; 2011 Jul 25.

7. Fendrick AM, Greenberg BP. A review of the benefits and risks of nonsteroidal anti-inflammatory drugs in the management of mild-tomoderate osteoarthritis. Osteopathic medicine and primary care. 2009 Dec;3(1):1-7.

8. Global Acetaminophen Market 2016 Industry Analysis, Segment Forecasts up to 2020, Research Reports-Market Research Store. 2016. Retrieved from: https://www.newswire.com/news/global-acetaminophen-market-2016-industry-analysis segment-forecasts-up-to-2020.

9. Graham GG, Scott KF, Day RO. Tolerability of paracetamol. Drug safety. 2005 Mar;28(3):227-40.

10. Geerthana R.; Nandhini P.; Suriyakala R.. "Medicinal Plant Identification Using Deep Learning". International Research Journal on Advanced Science Hub, 3, Special Issue ICITCA-2021 5S, 2021, 48-53.

11. Minakshee Sarmah; Nibir Kashyap; Dimpee Sonowal; Priety Chakravarty. "Screening of Bioactive compounds and antimicrobial properties from plant extracts of Biscofia javanica". International Research Journal on Advanced Science Hub, 2, Special Issue ICARD 2020, 2020, 256260. doi: 10.47392/irjash.2020.129

12. Kowshik B; Savitha V; Nimosh madhav M; Karpagam G; Sangeetha K. "Plant Disease Detection Using Deep Learning". International Research Journal on Advanced Science Hub, 3, Special Issue ICARD-2021 3S, 2021, 30-33. doi: 10.47392/irjash.2021.057

13. Sofowora A, Ogunbodede E, Onayade A. The role and place of medicinal plants in the strategies for disease prevention. African journal of traditional, complementary and alternative medicines. 2013 Aug 14;10(5):210-29.

14. Supriya D. Waghmare. "Ethnobotanical Survey on Antiurolithiatic Activity of Some Medicinal Plants". International Research Journal on Advanced Science Hub, 2, Special Issue ICARD 2020, 2020, 268-275. doi: 10.47392/irjash.2020.131

15. Nikhil Agnihotri; Sippy Dassani; Sharma T.K.. "Present Status and Conservation Strategies of Biodiversity in India". International Research Journal on Advanced Science Hub, 2, Special Issue ICARD 2020, 2020, 251-255. doi: 10.47392/irjash.2020.128

16. Anupam Verma; Vandana Srivastava. "Natural Resource Consumption and Lockdown". International Research Journal on Advanced Science Hub, 2, 6, 2020, 79-86. doi: 10.47392/irjash.2020.41 


\section{International Advanced Research Journal in Science, Engineering and Technology}

Vol. 8, Issue 8, August 2021

\section{DOI: 10.17148/IARJSET.2021.8801}

17. Takos AM, Rook F. Towards a molecular understanding of the biosynthesis of Amaryllidaceae alkaloids in support of their expanding medical use. International journal of molecular sciences. 2013 Jun;14(6):11713-41.

18. Rauf A, Jehan N, Ahmad Z, Mubarak MS. Analgesic potential of extracts and derived natural products from medicinal plants. Pain Relief-From Analog to Altern Ther Rijeka: InTech. 2017 May 24:339-51.

19. Chinnappan SM, George A, Thaggikuppe P, Choudhary Y, Choudhary VK, Ramani Y, Dewangan R. Nephroprotective effect of herbal extract Eurycoma longifolia on paracetamol-induced nephrotoxicity in rats. Evidence-Based Complementary and Alternative Medicine. 2019 May $13 ; 2019$.

20. Uthaya Kumar US, Chen Y, Kanwar JR, Sasidharan S. Redox control of antioxidant and antihepatotoxic activities of Cassia surattensis seed extract against paracetamol intoxication in mice: in vitro and in vivo studies of herbal green antioxidants. Oxidative medicine and cellular longevity. 2016 Jan 1;2016.

21. Petrovska BB. Historical review of medicinal plants usage. Pharmacognosy reviews. $2012 \quad$ Jan;6(11):1. 